\title{
RECOMPOSIÇÃO DA RELAÇÃO SUJEITO-TRABALHO NOS MODELOS EMERGENTES DE CARREIRA
}

RECONSTRUCTION OF THE SUBJECT-WORK RELATIONSHIP IN THE EMERGING MODELS OF CAREER

\section{RESUMO}

Nosso objetivo neste artigo é analisar a recomposição da relação sujeito-trabalho presente em modelos emergentes de carreira concebidos na confluência de tradições sociológicas, psicológicas e gerenciais. Utilizamos o termo recomposição, pois esses modelos têm em comum a partilha de um humor de época que se generalizou especialmente nos últimos quarenta anos, consistindo em enfatizar a fragilização, a precarização, a desmontagem e a consequente necessidade de transformação dos modelos de carreira tradicionais, calcados em torno da noção de emprego herdada da sociedade industrial. Apresentamos e analisamos os pressupostos centrais de oito modelos emergentes de carreira e questionamos como, a partir deles, sujeito, trabalho e organizações são reelaborados em resposta à desinstitucionalização do emprego observada no mesmo período em que eles foram propostos. Concluímos propondo que os modelos emergentes de carreira são dispositivos discursivos cuja crítica pode nos trazer informações valiosas sobre as ambiguidades e tensões do trabalho na atualidade.

\author{
Pedro F. Bendassolli \\ pedro.bendassolli@fgv.br \\ Recebido em 13.04.2009. Aprovado em 28.07.2009 \\ Avaliado pelo sistema double blind review \\ Editor Científico: Arnaldo José França Mazzei Nogueira
}

Professor da Escola de Administração de Empresas de São Paulo, Fundação Getulio Vargas - SP, Brasil

\begin{abstract}
The purpose of this article is to analyze the reconstruction of the subject-work relationship found in emerging career models emerging from the confluence of sociological, psychological and managerial traditions. We use the term reconstruction because these models share a common spirit of the times that became widespread over the past four decades and consists in emphasizing the weakening, precarization, disassembly and consequent need for transformation of traditional career models, seated on a concept of employment that is a heirloom from the industrial society. We introduce and analyze the central assumptions of eight emerging career models and, based on them, investigate how the subject, work and organizations are re-worked in response to the de-institutionalization of work that took place as they were proposed. We conclude by proposing that emerging career models are discursive devices whose criticism may yield valuable information on the ambiguities and contradictions surrounding work today.
\end{abstract}

PALAVRAS-CHAVE Carreira, modelos de carreira, significado do trabalho, indivíduo e organização, identidade profissional.

KEYWORDS Career, career models, meaning of working, individual and organization, professional identity. 


\section{INTRODUÇÃO}

Como outros conceitos das ciências sociais, o de carreira possui uma ambiguidade ligada ao fato de colecionar uma ampla diversidade de definições. Para citar poucos exemplos, carreira pode significar, ao mesmo tempo, emprego assalariado ou atividade não remunerada; pertencimento a um grupo profissional (sindicalizado ou não) ou a manifestação da mais pura idiossincrasia (a carreira de um artista); vocação (algo que alguém faz com alto nível de comprometimento afetivo) ou ocupação (algo que alguém faz por necessidade ou obrigação); posição em uma organização (associada a passagens por diversos cargos na hierarquia institucional) ou trajetória de um indivíduo que trabalha por conta própria; uma fonte de informação para as empresas alocarem recursos (humanos) ou então um roteiro pessoal para a realização dos próprios desejos.

Em parte, a coexistência dessas distintas formas de conceber a carreira tem a ver com a difusa produção discursiva sobre ela realizada nas disciplinas que, ao longo da história, se ocuparam diretamente das questões do trabalho. Pensamos em particular na sociologia do trabalho e das profissões, na psicologia do trabalho e na administração. Cada uma delas contribui, a seu modo, para a compreensão que temos hoje de carreira. Mas, ao falar sobre esse tema, elas estão também a falar sobre questões mais amplas e fundamentais, como as envolvidas na relação trabalho, sujeito, organizações e sociedade. Carreira aparece então como um conceito mediador capaz de ligar diversas dimensões da experiência humana em torno do trabalho.

Nosso objetivo neste artigo é analisar a recomposição da relação sujeito-trabalho presente em modelos emergentes de carreira concebidos na confluência de tradições sociológicas, psicológicas e gerenciais. Utilizamos o termo "recomposição", pois esses modelos têm em comum a partilha de um "humor de época" que se generalizou especialmente nos últimos quarenta anos, consistindo em enfatizar a fragilização, a precarização, a desmontagem e a consequente necessidade de transformação dos modelos de carreira "tradicionais", calcados em torno da noção de emprego herdada da sociedade industrial. Assim, não por coincidência o período que assistiu à emergência da tese sobre o "fim dos empregos" (RIFKIN, 2004) ou o "declínio da centralidade do trabalho" (MEDA, 1998) é também o que assistiu à proliferação de um sem-número de discursos, modelos ou metáforas de carreiras (INKSON, 2007).

Metodologicamente, o artigo é elaborado como um ensaio ao estilo "construcionista" (HOLSTEIN e GRUBRIUM, 2008), cuja lógica inclui uma "desfamiliarização" de termos tomados como verdades a priori. De fato, em diversas tradições do management - como nas de gestão de pessoas - modos de conceptualizar, investigar e intervir sobre as carreiras são tomados como certos, e raramente seus pressupostos são colocados em escrutínio e sob crítica. Na perspectiva construcionista, conceitos associam-se a discursos, os quais constituem "jogos da verdade", influenciados por certos propósitos, interesses, além de por um contexto sócio-histórico e econômico. Em linha com essa perspectiva, neste artigo tomamos oito modelos ditos emergentes de carreira como um corpus sobre o qual nos interessa questionar suas origens, premissas centrais e desdobramentos. Na perspectiva adotada, interessa-nos, especialmente, confrontar esse corpus a duas categorias de reconstrução analítica escolhidas como chaves - sujeito e trabalho - e isso com o intuito de investigar a contribuição desses modelos para a recomposição da relação homem-trabalho em momento de capitalismo hiperflexível.

Em termos mais específicos, o texto é estruturado em quatro partes, além desta introdução. Na primeira, sistematizamos algumas das grandes contribuições da sociologia, da psicologia e da administração para a compreensão do campo do trabalho e das carreiras. De escopo amplo e esquemático, o objetivo dessa seção é identificar repertórios de significados fornecidos por essas disciplinas sobre as relações entre trabalho, indivíduo e organizações e que, por esse motivo, influenciam, direta ou indiretamente, a construção dos modelos emergentes de carreira analisados na sequência do texto. Assim, na segunda parte reunimos e analisamos tais modelos em função de duas categorias analíticas: sujeito e trabalho. Nessa seção buscamos responder a duas questões: 1) qual o conceito de sujeito implícito nesses modelos; e 2) qual o conceito de trabalho apresentado nesses modelos, considerando: a) o significado do trabalho; b) a institucionalização do trabalho (sua organização). Na terceira seção integramos as duas questões levantadas na seção anterior e derivamos daí algumas questões críticas para os estudos da carreira na atualidade. Na quarta e última seção concluímos o artigo definindo nosso posicionamento em relação ao quadro teórico aqui delineado, bem como destacando algumas limitações e futuros desdobramentos deste artigo.

\section{REPERTÓRIOS DE SIGNIFICADOS SOBRE CARREIRA}

Discutimos nesta seção as principais contribuições da sociologia das profissões, da psicologia do trabalho e da administração (gestão de pessoas) para a compreensão das carreiras. 


\section{Sociologia das profissões}

A sociologia das profissões não fala diretamente em carreira no sentido comumente empregado pelos modelos emergentes de carreira a serem analisados na próxima seção. Na tradição anglo-saxônica, fala-se de profissão; na francófona, de métier. Em ambas trata-se de entender as profissões como um "corpo intermediário", no sentido durkheimiano. Realçam-se os aspectos organizativos dos grupos sociais em prol de seu reconhecimento, pelo Estado, como detentores de um saber legítimo e do direito de exercê-lo. Carreiras, por seu turno, estão mais próximas do sentido de carreiras organizacionais e, atualmente, de carreiras individuais - chegando-se ao extremo de tratar estas últimas como dependentes de características exclusivamente pessoais. Nesse ponto entendemos haver uma contribuição da sociologia das profissões ao estudo sobre carreira.

Trata-se da ideia de profissão como um objeto multideterminado, definido como um fenômeno ao mesmo tempo social, individual e institucional (DUBAR e TRIPIER, 2005). Do ponto de vista social, as profissões representam formas históricas de divisão e organização do trabalho. Como fenômeno individual, são formas de realização de si e de construção do indivíduo em sua experiência com o trabalho. Por fim, como fenômeno institucional, representam processos pelos quais os atores sociais defendem seus interesses na medida em que forçam o Estado a reconhecê-los como detentores de um conhecimento exclusivo e, portanto, autorizados a exercer uma profissão (um métier). Assim, contra o risco de se privilegiarem apenas os fatores individuais na construção das carreiras, a sociologia das profissões insiste sobre a necessidade de se reconhecer a existência de distintas dimensões na interpretação do fenômeno das profissões e, correlatamente, das carreiras.

Outra contribuição da sociologia das profissões radicase em sua discussão dos conceitos de papel e mobilidade social. Para a tradição sociológica conhecida como "escola da aquisição de status", a carreira é considerada principalmente do ponto de vista do indivíduo, vendo nele um problema de mobilidade intergeracional (LAPLANTE, 2003). Nesse caso é realçada a contribuição das instituições e das estruturas organizacionais dentro das quais os indivíduos desenrolam suas carreiras, as distintas cargas de prestígio e poder (status) associadas a cada ocupação (ou papel ocupacional) e os ritos de passagem ocupacional. As forças sociais agem como balizas, definindo o que é possível ou não em matéria de mobilidade - de um lado, existem as forças do meio familiar (do grupo primário) e da origem social do indivíduo; de outro, as regras ou os ritos de entrada, mobilidade e ascensão próprios de cada organização.
Carreira designa, nessa tradição, a evolução dos papéis sociais desempenhados pelos indivíduos. Tomam parte dessa linha argumentativa as ideias de socialização (meio pelo qual o indivíduo adquire as competências para ocupar um determinado papel social), de ocupação (uma função numa estrutura de cargos, por exemplo) e de interdependência funcional. Esta última ideia surge dos trabalhos de Carr-Saunders e Wilson (1933) e Parsons (1939). De acordo com ela, as profissões, e as carreiras a elas associadas, são parte de conjuntos de atividades humanas estreitamente ligados a grandes subsistemas, com suas funções especializadas e papéis definidos e interdependentes.

Entretanto, nos anos de 1930 esse modelo foi severamente abalado pelos pesquisadores da chamada Escola de Chicago (CHAPOULIE, 2001). Dentre eles, Everett Hughes é a referência principal. Hughes (1937), contra a tradição funcionalista da sociologia norte-americana das profissões inspirada por Parsons (1939), propõe a dissociação entre papel, status e pessoa no estudo das carreiras. No artigo mencionado, o autor define carreira de duas perspectivas: 1) objetiva, quando se realçam estrutura social, aspectos situacionais e interacionais, e as regras da profissão em questão, e 2) subjetiva. Neste último caso, diz Hughes (1937, p. 409-410), "uma carreira é uma perspectiva dinâmica pela qual a pessoa concebe sua vida como um conjunto e interpreta o significado de suas diversas características, das ações e das coisas que lhe ocorrem". Inspirada em uma perspectiva interacionista (DUBAR e TRIPIER, 2005), essa abordagem da carreira coloca em cena a dimensão temporal desta última, a capacidade do sujeito de interpretar suas próprias experiências e o efeito dos processos sociais.

Em relação estreita com a sociologia, veremos, no próximo item, as contribuições da psicologia do trabalho, especificamente da psicologia das profissões e da identidade profissional.

\section{Psicologia do trabalho}

A particularidade da apropriação psicológica do trabalho envolve a introdução de um vocabulário (ou discurso) próprio amparado em conceitos como os de vida psíquica, identidade, self, desenvolvimento e crescimento pessoais, subjetividade. $\mathrm{O}$ trabalho é soldado ao sujeito enquanto portador de dinâmicas psíquicas singulares, a um self ou $e u$ interiores. Assim, o homem psicológico é um sujeito cuja "vida interior" ganha espessura e densidade por comparação ao sujeito das tradições sociológicas funcionalistas (ênfase no sistema) e estruturalistas (ênfase em padrões predeterminados e compartilhados) ou mesmo, no interior do campo, das tradições comportamentalis- 
tas. A primeira contribuição da psicologia ao estudo das carreiras é sua ênfase na singularidade e na natureza "interpretativa" do sujeito.

Historicamente, essa mudança de perspectiva está associada a uma transformação maior dentro da psicologia, a qual veio a ser conhecida como "virada cognitivista". A partir de dela, questões envolvendo significado ganharam um novo status epistemológico. O sujeito passa a ser compreendido como alguém capaz de construir-se a si mesmo por meio da atribuição e interpretação de significados ou do processamento de informações. Quando associada a influências fenomenológicas e hermenêuticas, essa perspectiva "construcionista" do sujeito é complementada com a ideia de narratividade, sendo o self um produto de uma história que o indivíduo conta de si para si mesmo. Quando associada a influências culturais e sociais, como a do interacionismo simbólico, por exemplo, o selfé analisado em sua inter-relação entre uma história singular e uma história coletiva.

A virada cognitiva lança novas luzes à compreensão das carreiras. Primeiro, carreira é o resultado de um processo de construção pelo qual o indivíduo significa, interpreta e dá coerência a suas experiências e histórias singulares de vida em relação ao trabalho (e à vida como um todo). Este último é considerado uma dimensão importante da subjetividade humana, pois, por meio dele, o indivíduo pode construir a consciência de si mesmo e, colocando-o numa perspectiva temporal, de acompanhar seu processo de desenvolvimento, de movimentação em direção ao alcance de seus ideais, desejos ou da satisfação de suas necessidades.

Outra contribuição da psicologia ao estudo das carreiras ocorre no campo do desenvolvimento pessoal e profissional. Emblemática, nesse ponto, é a psicologia vocacional. Esse subcampo da psicologia ocupou-se originalmente do ajuste da pessoa ao papel ocupacional, ou da correspondência entre indivíduo e cargo, indivíduo e profissão. Foram propostas ideias como "personalidade vocacional" (HOLLAND, 1973), "disposições vocacionais", ajustamento entre "carreira interna" (motivos, valores, desejos) e as possibilidades de realizá-la na estrutura social das profissões e do mercado (SCHEIN, 1978). Com o passar do tempo, lembra-nos Savickas (2001), a psicologia vocacional reorientou esse seu foco do ajuste da pessoa ao trabalho para o ajuste deste àquela. Duas linhas merecem destaque nesse sentido: a do desenvolvimento profissional (SUPER, 1957, 1990) e da carreira como componente da estrutura de vida de um indivíduo, como uma forma de aceder à vida adulta (LEVINSON, 1984).

A "teoria da construção da carreira" (SAVICKAS, 2001; 2005), calcada na teoria do desenvolvimento vocacional de Super (1957), propõe que as profissões são um papel fundamental em torno do qual se organiza a estrutura da personalidade dos indivíduos. Especificamente, a carreira é o veículo pelo qual estes últimos se autorrealizam e desenvolvem seu autoconceito, a ideia que têm de si mesmos ao longo de seu processo evolutivo de maturação. Dá-se ênfase aos padrões de experiência pessoais, aos temas de vida, às estórias biográficas e aos momentos ou fases pelas quais o indivíduo passa à medida que avança no desempenho de um papel ocupacional. Uma contribuição dessa teoria ao estudo das carreiras é a associação do autoconceito (ou identidade) a estruturas ocupacionais objetivas, insistindo no papel ativo do indivíduo na construção de seu projeto profissional, e a ideia de que carreira é o veículo para o desenvolvimento e a autorrealização pessoais.

Uma última contribuição da psicologia que destacamos é a de identidade. Esse conceito tem o poder de nos permitir captar as ressonâncias individuais do processo de desconexão entre o conceito moderno de trabalho, o emprego, e das identidades a ele associadas. Por essa razão, estudos focados na relação trabalho e identidade têm, como pano de fundo, a ideia de "crise" (por exemplo, DUBAR, 2000; GARNER, MÉDA e SENIK, 2006; OSTY, 2008; WOLFGANG, 1998; CASTEL, 1999; EZZY, 1997; COLLINSON, 2003; SENNETT, 1998). Encontramos nesses estudos reflexos das tensões entre carreira como um papel associado a um cargo numa estrutura organizacional (estável ou quase estável) e carreira enquanto um projeto autorreflexivo do eu, insistindo no caráter dinâmico da identidade e na capacidade de resposta do indivíduo em face das mudanças do ambiente social e profissional.

Por fim, discutimos na sequência algumas das principais contribuições da Administração, especialmente no ramo da gestão de pessoas, à nossa compreensão de carreira.

\section{Administração}

Como destacam Adamson, Doherty e Viney (1998) em um artigo de revisão sobre os diversos significados de carreira, já no final dos anos de 1970 o campo da gestão possuía tal grau de desenvolvimento conceitual que podia arrogar para si uma teoria de carreira própria. Corroborando a visão desses autores, podemos citar o lançamento, num intervalo de dezoito anos, de dois importantes handbooks organizados por Arthur, Hall e Lawrence (1989) e Gunz e Peiperl (2007), respectivamente, para não mencionar o sem número de periódicos dedicados direta e indiretamente ao tema.

Identificamos algumas características comuns nas abordagens gerenciais das carreiras. Em primeiro lugar, são conduzidas na dupla perspectiva do indivíduo e da organização. Como consequência, a contribuição dessas 
abordagens é, conforme identifica Gunz (1989), a diferenciação de dois níveis de análise nos estudos de carreira: o nível organizacional (carreira como estruturas e rotinas) e o nível individual (carreira subjetiva e estratégias de carreira). Evetts (1992) acrescenta um terceiro nível: o da agência e o da estrutura.

Do ponto de vista das organizações, carreira é um dispositivo que permite a alocação de recursos, o subsídio à tomada de decisão sobre esquemas de mobilidade e o gerenciamento simbólico do nível de comprometimento de seu pessoal. Do ponto de vista do indivíduo, carreira funciona como um dispositivo para a organização da experiência subjetiva com o trabalho, como um repositório de racionalizações para ele interpretar (e justificar) os eventos que lhe ocorrem no campo profissional (por exemplo, uma demissão, uma promoção), como um apoio à tomada de decisão sobre rumos futuros a seguir ou sobre o que fazer com as oportunidades que se abrem e se fecham, e como um recurso.

As teorias motivacionais propostas na abordagem gerencial são uma outra boa fonte para captarmos outras contribuições dessa linha ao estudo das carreiras. Em geral, nessas teorias o indivíduo é visto (1) como alguém impelido a um processo de autodesenvolvimento e de autorrealização na medida em que satisfaz necessidades progressivamente complexas; e (2) como um indivíduo (semi-)racional, maximizador de seus ganhos, capaz de negociar entre expectativas pessoais e exigências que pesam sobre seu desempenho. Sob a influência dessas ideias, as carreiras tornam-se preditoras ou são associadas a constructos tais como nível de motivação, satisfação no trabalho, comprometimento organizacional, desempenho individual e sucesso.

$\mathrm{Na}$ sequência deste artigo analisamos, detalhadamente, cada um de oito modelos emergentes de carreira. Metodologicamente, isso será feito a partir de uma descrição do núcleo propositivo de cada modelo, conforme se pode encontrar na literatura especializada sobre o tema. Na próxima seção, confrontamos esses oito modelos contra dois conceitos ou categorias conceituais chaves neste artigo: a de sujeito e trabalho. Assim, nossa estratégia consistirá em refletir sobre os conceitos de sujeito e os significados de trabalho "ocultos" nesses oito modelos emergentes de carreira.

\section{REVISÃO E ANÁLISE DOS MODELOS EMERGENTES DE CARREIRA}

Denominamos modelos emergentes de carreira as propostas que, ao longo das últimas quatro décadas, buscam responder às transformações pelas quais passaram o trabalho, as organizações e as sociedades industriais e que têm, em seu centro, um diagnóstico sobre a elevação da incerteza, o risco, a fragilização e a ruptura dos vínculos tradicionais de trabalho. Em específico, analisamos nesta seção oito de tais modelos (Quadro 1). Em seu conjunto, eles captam e reelaboram os repertórios de significados das tradições sociológica, psicológica e gerencial, e propõem novas metáforas (INKSON, 2007), novos discursos sobre o que são, como se constroem e como se gerenciam (funções de RH) as carreiras na atualidade.

\section{Proposições dos modelos}

O Quadro 1 sumariza as pressuposições dos oito modelos emergentes de carreira sobre os quais faremos uma síntese na sequência.

Em primeiro lugar, temos o modelo da carreira sem fronteiras, originalmente proposto por Arthur (1994) e Arthur e Rousseau (1996), que gerou subsequentes estudos (STEPHENS, 1994; LIPS-WIERSMA e MCMORLAND, 2006; JACKSON, 1996; CURRIE, TEMPES E STARKEY, 2006; SULLIVAN e ARTHUR, 2006), sendo mesmo questionado (PRINGLE e MALLON, 2003; WALTON e MALLON, 2004). Essas carreiras se opõem às de tipos tradicionais precisamente pelo fato de não serem confinadas às fronteiras de uma única organização, emprego, ocupação, região ou domínio de expertise. Pelo contrário, elas implicam uma pluralização dos contextos de trabalho e um tipo de contrato psicológico (ROUSSEAU, 1995) baseado na relação instável, e movida a oportunidades, de um indivíduo com sua organização. O modelo propõe uma transversalidade dos vínculos de trabalho e não, como o modelo tradicional, uma verticalidade pela qual o indivíduo devotava às vezes toda a sua vida a uma organização, função ou ocupação. Outro pressuposto importante desse modelo é que, para sustentar uma carreira sem fronteiras, o indivíduo deve cultivar três competências: primeiramente, ele deve conhecer os motivos de seu engajamento profissional, seus valores, necessidades e interesses. DeFilippi e Arthur (1994) denominam essa competência "saber por quê", ou know-why. A segunda competência consiste no "saber fazer", ou know-how. Por último, a competência "saber com quem", ou know-whom, diz respeito ao papel das redes sociais.

O segundo modelo é o da carreira protiana. Concebido por Hall $(1976$; 2002; 2004) e, como o anterior, debatido na literatura (SARGENT e DOMBERGER, 2007; MCDONALD, BROWN E BRADLEY, 2005; CROWLEYHENRY e WEIR, 2007; CROWLEY-HENRY, 2007), esse modelo empresta da mitologia grega uma metáfora para 
realçar a inevitabilidade das mudanças. Proteu, deus do mar, mudava de face como resposta adaptativa, e estratégica, às mudanças no ambiente. A mensagem é clara: carreira depende de versatilidade, contínua adaptação e resiliência. A carreira protiana é uma construção dividida entre mudança e permanência: de um lado, o "profissio-

Quadro 1 - Modelos emergentes de carreira

\begin{tabular}{|c|c|c|c|}
\hline MODELO & PROPOSIÇÕES & SUJEITO & TRABALHO \\
\hline $\begin{array}{l}\text { Carreira sem } \\
\text { fronteiras }\end{array}$ & $\begin{array}{l}\text { - Pluralidade de contextos de trabalho } \\
\text { - Transversalidade dos vínculos com as organizações } \\
\text { - Competências (know-why, know-how e know-whom) }\end{array}$ & \multirow{3}{*}{ Agente } & $\begin{array}{l}\text { - Campo privilegiado da ação } \\
\text { individual } \\
\text { - Arranjo instável de trocas mútuas } \\
\text { entre indivíduo e organização }\end{array}$ \\
\hline $\begin{array}{l}\text { Carreira } \\
\text { protiana }\end{array}$ & $\begin{array}{l}\text { - Mudança como um dado de realidade } \\
\text { - Variedade de experiências } \\
\text { - Adaptabilidade e resiliência } \\
\text { - Identidade como âncora }\end{array}$ & & $\begin{array}{l}\text { - Meio de externalização da } \\
\text { identidade pessoal } \\
\text { - Sequência de experiências } \\
\text { pessoais }\end{array}$ \\
\hline $\begin{array}{l}\text { Craft } \\
\text { career }\end{array}$ & $\begin{array}{l}\text { - Autonomia, criatividade, invenção e reinvenção do } \\
\text { próprio trabalho } \\
\text { - Sujeito e atividade como um único conjunto } \\
\text { - Trabalho e sensemaking }\end{array}$ & & $\begin{array}{l}\text { - Trabalho como "fluxo" } \\
\text { - Modelo de organização artesanal } \\
\text { de trabalho }\end{array}$ \\
\hline $\begin{array}{l}\text { Carreira } \\
\text { portfólio }\end{array}$ & $\begin{array}{l}\text { - Diversificação das atividades profissionais } \\
\text { - Flexibilização das identidades pessoais } \\
\text { - Múltiplas zonas de expertise individual }\end{array}$ & \multirow{2}{*}{ Pós-moderno } & $\begin{array}{l}\text { - Trabalho como um elemento dentre } \\
\text { outros do espaço de vida pessoal } \\
\text { - Trabalho fragmentado, em tempo } \\
\text { parcial }\end{array}$ \\
\hline $\begin{array}{l}\text { Carreira } \\
\text { multidirecional }\end{array}$ & $\begin{array}{l}\text { - Não linearidade das experiências de trabalho } \\
\text { - Contrato psicológico transacional } \\
\text { - Comprometimentos múltiplos }\end{array}$ & & $\begin{array}{l}\text { - Trabalho como um suporte para a } \\
\text { construção da identidade pessoal } \\
\text { - Flexibilidade do trabalho }\end{array}$ \\
\hline $\begin{array}{l}\text { Carreira } \\
\text { transicional }\end{array}$ & $\begin{array}{l}\text { - Interdependência entre agência individual e estrutu- } \\
\text { ra social } \\
\text { - Carreira como mediação entre instituições e proces- } \\
\text { sos de interação } \\
\text { - Processo de contínua construção e reinterpretação } \\
\text { de scripts }\end{array}$ & Reflexivo & $\begin{array}{l}\text { - Trabalho-portfólio } \\
\text { - Desregulamentação institucional } \\
\text { do trabalho }\end{array}$ \\
\hline $\begin{array}{l}\text { Carreira } \\
\text { narrativa }\end{array}$ & $\begin{array}{l}\text { - Temporalidade e ação como processos narrativos } \\
\text { - Interpretação de eventos da realidade e do self } \\
\text { - Narrativa e projeto } \\
\text { - Carreira entre história coletiva e história singular }\end{array}$ & \multirow{2}{*}{ Interacional } & $\begin{array}{l}\text { - Trabalho como narrativa social e } \\
\text { pessoal } \\
\text { - Trabalho como fato “objetivo" } \\
\text { apresentado à interpretação (e } \\
\text { reinterpretação) }\end{array}$ \\
\hline $\begin{array}{l}\text { Carreira } \\
\text { construcionista }\end{array}$ & $\begin{array}{l}\text { - Carreira como um processo de construção social e } \\
\text { de interação } \\
\text { - Identidade como metamorfose } \\
\text { - Processos de negociação de significados no contexto } \\
\text { de estruturas sociais }\end{array}$ & & $\begin{array}{l}\text { - Trabalho como um processo } \\
\text { discursivo } \\
\text { - Compartilhamento de valores e } \\
\text { objetivos comuns }\end{array}$ \\
\hline
\end{tabular}


nal herói" (INKSON, 2007) reage adaptativa e resistentemente a uma época de transformações e a um contexto socioeconômico turbulento; de outro, ele necessita de um senso de autodireção, o qual Hall (2002) situa na esfera da identidade pessoal, tomada como âncora (SCHEIN, 1993). Assim, a identidade, representando o autoconceito do indivíduo, funciona como uma bússola de orientação pela qual o indivíduo desenha o curso a seguir e a ação a tomar.

Em terceiro, comentamos o modelo da craft career. O ideal no qual ele se baseia é o artesão. Como consequência, revisita as características historicamente associadas a esse tipo de trabalho, tais como a autonomia do artesão em conceber sua obra e organizar suas atividades; o uso intensivo da criatividade; a ausência de mediação entre o sujeito que trabalha e o resultado produzido; o engajamento afetivo com a atividade (POEHNELL e AMUNDON, 2002; WRZESNIEWSKI e DUTTON, 2001). Nesse sentido, a carreira é apresentada do ponto de vista do job-crafter, alguém capaz de construir seu trabalho à sua maneira, seja do ponto de vista físico, cognitivo ou relacional. Baseado no conceito de "fluxo" proposto por Csikszentmihalyi (1990), a atividade de trabalho é apreendida como um movimento no qual o indivíduo engaja intensamente corpo e mente. Como metáfora, entendemos que esse modelo se aproxima do trabalho de tipo artístico, recentemente apropriado como metáfora do trabalho (MENGER, 2003).

O quarto modelo é a carreira portfólio. Aqui a carreira é descrita a partir da diversificação das atividades profissionais de que é capaz o indivíduo, consistindo ainda em sequências fragmentadas de trabalhos. O indivíduo pode optar por trabalhar apenas em um regime parcial e dedicar o restante de seu tempo a atividades fora do trabalho ou mesmo em frentes diferenciadas de trabalho (BORGEN, AMUNDSON e REUTER, 2004). Para isso acontecer, dois aspectos devem caminhar juntos: primeiro, a carreira portfólio depende de uma identidade pessoal flexível. Talvez seja difícil a uma pessoa, para quem o trabalho é uma esfera de vida central (portanto, de onde retira o significado de sua identidade), adotar uma carreira de tipo portfólio, pois isso exigirá que distribua seu tempo em diversas atividades, algumas das quais não relacionadas ao trabalho. Em segundo lugar, é preciso haver o acompanhamento dos desenhos organizacionais. Do contrário, indivíduos com uma carreira portfólio podem ver suas chances de ascensão minimizadas. Alternativamente, a carreira portfólio pode significar que o indivíduo opta por atuar em múltiplas zonas de expertise, disponibilizando uma "carteira" de trabalhos a contratantes potenciais (INKSON, 2007).

A carreira multidirecional é o quinto modelo. Ele é proposto por Baruch $(2004 ; 2006)$, que o contrapõe às carreiras tradicionais. Enquanto estas últimas eram lineares, dependentes da estrutura e cultura da organização, oferecendo aos indivíduos uma única rota ascendente, as carreiras multidirecionais são flexíveis, dinâmicas e abertas a distintas e igualmente válidas direções e possibilidades. Por exemplo, o sucesso não é definido unicamente vis-à-vis o encadeamento hierárquico (o gerente se tornando diretor), mas a multifacetados movimentos laterais, recuos e trocas completas do terreno a percorrer. A carreira não possui uma meta externa, determinada pelos papéis ou funções da estrutura da organização: ensaiando e errando, o indivíduo vai revendo seus objetivos e alterando seu foco.

Em sexto, temos a carreira transicional, apresentada por Duberley, Mallon e Cohen (2005). Esses autores criticam a divisão entre agência e estrutura observada na literatura sobre carreiras. Segundo eles, essa divisão culmina ora em uma hipervalorização dos fatores individuais, de natureza psicológica, ora dos fatores estruturais, de natureza social, na interpretação das carreiras. Em contrapartida, sugerem a inter-relação entre essas duas dimensões da ação. Propondo uma compreensão da carreira como um processo de transição entre esquemas tradicionais de trabalho para esquemas que denominam "trabalho-portfólio", Duberley, Mallon e Cohen destacam que, apesar de os indivíduos seguirem roteiros predefinidos e instituídos, eles, quando da transição, têm igualmente de reinventar seu modo de ação. Neste último caso, a agência individual contribui com a construção de novos roteiros para a carreira.

O sétimo modelo é o da carreira narrativa. Nele, carreira refere-se a uma organização dos eventos de trabalho de uma pessoa em uma história significativa para ela. O selfé responsável por processar os eventos e fatos dispersos da vida profissional e transformá-los em episódios e enredos articulados casualmente e coerentemente no tempo e no espaço (BUJOLD, 2004; COCHRAN, 1990). Nesse processo de interpretação, o indivíduo conta com as narrativas sociais e históricas, as quais, como no modelo anterior, disponibilizam amplos repertórios de significados. Assim, ao construir uma narrativa sobre sua vida profissional, o indivíduo está, ao mesmo tempo, posicionado em uma rede composta por valores, instituições, regras e práticas simbólicas e materiais, e confrontado com seus desejos, valores e necessidades próprios.

Por fim, temos a carreira construcionista. Nessa proposta a carreira não é um "dado objetivo" da realidade (organizacional), mas um processo em permanente construção, para o qual contribuem os discursos sociais, os processos de interação do indivíduo e um determinado contexto econômico (BLUSTEIN, SCHULTHEISS e FLUM, 2004; 
COHEN, DUBERLEY E MALLON, 2004). Trata-se de um modelo de carreira construído à custa do movimento do construcionismo social (COLLIN e YOUNG, 2000), que, entre outras coisas, questiona a visão segundo a qual há uma verdade objetiva que existe independentemente dos interesses dos sujeitos e de relações de poder. Os autores que partilham dessa visão construcionista pretendem questionar as definições convencionais e estabelecidas de carreira. Por exemplo, o conceito de identidade vocacional (BLUSTEIN, 1994): em vez de ser entendida como o desdobramento "objetivo" de disposições interiores, ela o é como uma metamorfose, um contínuo jogo de interpretação e reinterpretação de discursos e repertórios sociais, e de experiências de interação interpessoal em torno do trabalho.

A seguir, ocupamo-nos de nosso segundo objetivo nesta seção: a análise do conceito de sujeito e do significado de trabalho "ocultos" ou pressupostos pelos oito modelos emergentes de carreira que acabam de ser descritos.

\section{Sujeito e trabalho}

O Quadro 1 mostra os conceitos de sujeito e trabalho presentes nos modelos emergentes de carreira. Para facilitar nossa análise, vamos dividi-los em quatro grandes grupos, embora essa divisão não implique que sejam categorias mutuamente excludentes. Como discutiremos adiante, eles sobrepõem-se em diversos pontos, haja vista partilharem de representações de época comuns. Em relação ao sujeito, os conceitos têm em comum a ênfase na autonomia, no desprendimento das tradições, na individualização e num posicionamento ativo diante dos repertórios socioculturais herdados. Em relação ao trabalho, os pontos em comuns são a constatação da desinstitucionalização tradicional do trabalho, materializada pela crise do emprego; pela transformação dos vínculos indivíduoorganização; pela não linearidade das carreiras; e pela reinstitucionalização do trabalho enquanto experiência, fluxo e contexto de desafios para o sujeito. Vejamos as características de cada grupo.

O primeiro grupo adota a perspectiva do sujeito como agente. Em linhas gerais, trata-se de um sujeito "desinibido", capaz de agir independentemente de fatores ambientais restritivos. A fonte da ação está em seu próprio interior, apresentado como um reservatório de recursos, competências e automotivação. Desse modo, ele não depende de uma organização a lhe indicar o caminho e a lhe demandar uma ação. Desincorporado de estruturas sociais, autônomo e capaz de decidir seu próprio destino, é um empreendedor de si mesmo (EHRENBERG, 1991) ou um ator livre (DANY, 2003). Essa referência ao su- jeito como agente associa-se, na literatura de carreiras, a conceitos que enfatizam a autoeficácia, a autogestão e o autodesenho da própria carreira (NEVILL e SCLECKER, 1988; STICKLAND, 1996; KING, 2004).

Em relação ao trabalho, observamos nesse grupo uma tendência a desvinculá-lo da representação do emprego e do empregado - categorias importantes em diversas tradições sociológicas. Nesses modelos, a carreira é definida como a "evolução das experiências de trabalho de um indivíduo ao longo do tempo" (ARTHUR, HALL e LAWRENCE, 1989, p. 8). Assim, o trabalho é associado a um campo de experiências ou de "fluxo" (modelo do craft career), cabendo ao sujeito (enquanto agente) responsabilizar-se pelo seu destino profissional, muitas vezes sem recursos internos suficientes (CASTEL, 2009; EHRENBERG, 1995).

O segundo grupo adota a ideia do sujeito pós-moderno. Metaforicamente, trata-se do sujeito com identidades múltiplas (ELSTER, 1985), sem um objetivo único ao qual se dedicar, nem uma tradição em que se fixar. Individualizado (BECK e BECK, 2001), arrisca-se em busca dos projetos que possam materializar seus interesses $\mathrm{e}$ desejos. Sua identidade é antes autodeclarada do que imposta pelas estruturas sociais (HEINICH, 2000). Aplicado à carreira, é o sujeito cuja identidade não se prende a uma única atividade, empresa ou ocupação. Há uma saliência de identidades (SUPER e SVERKO, 1995) em seu repertório, sendo a do trabalho apenas mais uma entre outras.

A nosso ver, pós-modernidade em matéria de trabalho é convergente com a ideia de transição do tradicional para o novo, presente nos modelos emergentes de carreira. No primeiro, o emprego representava parte expressiva da identidade social de uma pessoa, sendo a identidade atribuída um elemento fundamental na compreensão do papel e do valor da carreira nesse contexto, pois a ocupação era uma fonte de status. Na mentalidade atual, emergente, o trabalho transforma-se em um suporte para a realização do projeto reflexivo do eu: ele é usado para expressar um estilo pessoal, para o cultivo de experiências e competências singulares, num movimento contínuo de vinculação e desvinculação institucional. O trabalho fragmentado, esvaziado de conteúdos sociais emancipatórios (HONNETH, 2007), é a outra face das carreiras portfólio e multidirecionais.

O terceiro grupo é o do sujeito reflexivo. Neste há um reconhecimento mais explícito, comparativamente aos anteriores, da tensão entre agência e estrutura social na determinação da ação (GIDDENS, 1991). O sujeito reflexivo é capaz de receber as informações do ambiente, como os roteiros de significados produzidos pelas instituições sociais, e de confrontá-los com sua autoconsciência. A ação e a carreira tornam-se um fenômeno comple- 
xo dependente da confluência de múltiplas dimensões: individuais, interacionais, ambientais e contextuais. $\mathrm{O}$ trabalho é reelaborado como terreno de provas e desafios individuais (MARTUCCELLI, 2006), como um "trabalho sobre si" (DUBET, 2000) ou como fator de individualização (BECK e BECK, 2001).

Por fim, propomos a leitura do quarto grupo a partir da ideia de sujeito interacional. $\mathrm{O}$ aspecto central desse modelo de sujeito é o caráter construído da realidade e do self. Das interações emergem padrões compartilhados de significado assentados em narrativas ou discursos diante dos quais os sujeitos podem posicionar-se passiva ou ativamente. São passivos quando tomam esses discursos como aspectos reificados da realidade (EVETTS, 1992). Nesse caso, o sujeito é destituído de seu poder de ação e de produção de novas verdades ou conhecimentos. Aplicada ao campo da carreira, esta ideia sugere o "aprisionamento" do sujeito em roteiros pré-instituídos pelas organizações. Em contrapartida, quando assume postura ativa, o sujeito "desconstrói" esses discursos e propõe novas combinações de significados e novos arranjos para as estruturas sociais onde as carreiras estão encaixadas.

Os dois grupos anteriores, especialmente o quarto, reelaboram o significado e a organização do trabalho de forma mais matizada que os dois primeiros. O trabalho é reconhecido como uma narrativa/discurso pessoal e também social. A construção da carreira se faz com o suporte de ambas as fontes de significados, sendo seu ponto de ligação. O foco se volta para o modo como as pessoas compreendem, constroem e agem, mediante suas carreiras, nos múltiplos contextos de trabalho. Nessa perspectiva parece não fazer sentido a distinção entre carreira subjetiva e carreira objetiva, pois não se admite um "mundo exterior" ao sujeito, mais "objetivo" e "concreto" do que aquele moldado pela linguagem. São os aspectos comunicacionais e discursivos do trabalho que vêm para o primeiro plano (GAY, 1996).

Considerando a proposição dos modelos e os conceitos de sujeito e trabalho neles implicados, trataremos, na sequência, de algumas questões que emergem em torno deles e que julgamos críticas para o estudo e a pesquisa sobre carreiras na atualidade.

\section{QUESTÕES CRÍTICAS PARA 0 ESTUDO DA CARREIRA}

A maioria dos modelos emergentes analisados na seção anterior foram concebidos dentro da tradição gerencial, embora se apropriando de elementos disponibilizados pelas tradições sociológica e psicológica. Como resultado, diversas das proposições desses modelos não são totalmente inéditas, mas recomposições discursivas desses elementos sob um propósito renovado: a elaboração de respostas práticas para se gerar coerência entre, de um lado, o desarranjo dos vínculos empregatícios e contratos psicológicos emergentes, alterações institucionais das organizações em função de pressões competitivas e, de outro, as novas representações do sujeito.

Mudanças nas formas de conceber as organizações são seguidas (ou são acompanhadas) de novos modelos de carreira. Assim, estruturas mais flexíveis, projeto-intensivas, menos hierarquizadas, orientadas para gestão de conhecimento, dependentes de criatividade e de outras competências softs, coexistem, no plano das teorizações e das práticas de gestão de recursos humanos, com a ideia de que o indivíduo deve construir sua carreira em posição de independência relativa das organizações. Também é reveladora a rearticulação, de início no nível do discurso (LEGGE, 2005), da posição da área de Recursos Humanos, agora muito mais apresentada como uma facilitadora do desenvolvimento individual do que sua tutora. Não resta dúvida de que os modelos emergentes de carreira ajudaram nesse reposicionamento institucional do campo da gestão de pessoas.

A despeito de suas sutis diferenças, os quatro conceitos de sujeito discutidos anteriormente emergem da lacuna entre papel social e identidade pessoal, entre atribuição/ designação e uma identidade autopercebida/autoatribuída. Quanto mais o sujeito se distancia de seu papel social, mais ele pretensamente se individualiza e mais sua ação depende dele mesmo enquanto agente livre. O mesmo ocorre com o trabalho: quanto mais seu significado e sua organização se distanciam de uma institucionalização social, mais ele se transforma em um fluxo de experiências pelo qual a identidade pessoal se autoafirma. Nesse sentido, os modelos de carreira tomam parte do quadro mais amplo de discussões sobre a transição da modernidade para a pós-modernidade (ou modernidade tardia). Eles estendem as tendências "diluentes" desta última ao campo do trabalho, mas também herdam suas ambiguidades e tensões, das quais nos ocuparemos no restante deste artigo. Para isso, levantamos duas questões críticas: a da mudança e a da autonomia da ação.

\section{Carreira e mudança}

A mudança parece ser uma categoria comum a todos os modelos emergentes de carreira. Do sujeito como agente ao sujeito interacional, a mudança é um dado do contexto com o qual ele deve lidar. Para isso, lança mão de dis- 
tintos instrumentais: competências, no caso do agente; capacidade cognitiva autorregulatória para reelaborar o material recebido das estruturas sociais, no caso do sujeito reflexivo; diversificação e fragmentação, no caso do sujeito pós-moderno; ou ainda as narrativas elaboradas pelo sujeito interacional.

Se abordarmos a questão da mudança do ângulo da identidade, poderemos ver emergir uma primeira ambiguidade ou tensão com a qual se deparam os modelos emergentes de carreira: aquela entre mudança e permanência. Como vimos anteriormente, a associação entre identidade e carreira é uma contribuição da psicologia que permite a apreensão dos impactos psicológicos da desinstitucionalização do emprego tradicional. Ocorre que, ao contrário do modelo da carreira protiana, por exemplo, o qual parece privilegiar um processo de autoatribuição de identidade, a discussão psicológica sobre esse tema é mais complexa, ao menos se considerarmos a tradição da psicologia social (FARR, 1996): ao lado da identidade pessoal (autoatribuída) há também a identidade social. Esta última refere-se aos processos normativos de designação identitária nos quais a agência individual está incorporada.

Outro modo de colocar a tensão entre identidade pessoal e identidade social é referir-se aos processos correlatos de individualização e socialização. Em nosso entender, a especificidade das tradições sociológicas de estudo das carreiras nos fazer ver que os sistemas sociais "ainda" existem ao lado dos sistemas individuais, assim como determinadas realidades profissionais, com suas regras e estruturas de poder, com suas interações com o Estado e a sociedade (FREIDSON, 1994; EVETTS, 2003). Porém, discussões dessa natureza não estão explicitamente presentes em, pelo menos, cinco dos primeiros modelos apresentados no Quadro 1. Da mesma forma, estudos sobre classe social, origem familiar, nível socioeconômico e educacional e seus impactos sobre mobilidade ocupacional (por exemplo, ULRICH e CARROLL, 1987; PERRUCCI e PERRUCCI, 1970; PARKER, 1981) são poucos frequentes na literatura recente de carreiras. Há, contudo, exceções. Por exemplo, os estudos que, a partir dos anos 1990 (ADAMSON, DOHERTY e VINEY, 1998), discutem discriminações, diferenças de mobilidade, sucesso, remuneração etc. de mulheres, negros, grupos minoritários, portadores de deficiências ou doenças e estudos avaliando o impacto de diferenças interculturais.

Como preservar a tensão entre dimensões pessoais e sociais na construção da identidade de trabalho? Um exemplo nessa direção, oriundo do campo da formação profissional, é o de projeto (KADDOURI, 1996, 2002; BOUTINET, 1990; COCHRAN, 1997). Ele vem sendo proposto como um dispositivo para se manejar as instabilidades e incertezas do trabalho e seus impactos sobre a constituição das identidades pessoais e profissionais; para integrar orientações desenvolvimentais, interacionistas/ construcionistas e fenomenológicas (carreira como narrativa); e também para ajudar na intervenção em transições ou em descontinuidades profissionais.

\section{Carreira e autonomia}

Vejamos agora a questão da autonomia da ação, outra dimensão-chave dos modelos de carreira. Segundo Chen (2006), a questão da agência humana na psicologia vocacional foi colocada inicialmente em referência aos trabalhos de Bandura (1977, 1986), especificamente a seu conceito de autoeficácia (por exemplo, BETZ e HACKETT, 1987; CHEN, 2002; COCHRAN e LAUB, 1994; BETZ e FITZGERALD, 1987). O pressuposto central desse conceito é que a ação humana depende de uma autopercepção do indivíduo como sendo seu agente causador (intencionalidade) e de que ele exerce controle sobre a natureza e a qualidade de sua própria vida. Para Chen (2006), essa perspectiva traz consideráveis contribuições à compreensão das carreiras em uma era pós-moderna e pós-industrial, quando se observam grandes incertezas e transformações na relação do sujeito com seu trabalho. Em um contexto de alta individualização, como se acredita ser o pós-moderno (BECK e BECK, 2001), parece fazer sentido o motor da ação se instalar na órbita individual.

Em uma contextualização mais ampla, Knorr-Cetina e Cicourel (1981) destacam que uma importante transformação no modo de compreender a ação humana ocorre quando se passa, no plano das teorizações, de um conceito de ordem normativa, em que a ação é determinada pela estrutura e pelo sistema sociais, para um de ordem cognitiva, quando a ênfase é colocada sobre a maneira como as coisas são compreendidas pelos sujeitos. Como resultado, o foco se desloca dos macroproblemas da ação para seus microproblemas. Similarmente, as carreiras podem ser analisadas em seus microprocessos, como motivação, desejos, valores, intenção, significados, mas também do ponto de vista dos macroprocessos que elas próprias ajudam a construir e pelos quais são reciprocamente influenciadas. Nesse sentido, Evetts (1992) sugere que as investigações sobre carreiras deveriam questionar o interrelacionamento, as ambiguidades e tensões dos processos objetivadores e subjetivadores, isto é, como as estruturas moldam aspectos da "carreira subjetiva" e, alternativamente, como esta pode modificar as estruturas das carreiras.

Por fim, concluímos este artigo posicionando-nos em relação ao quadro teórico apresentado ao longo de seu 
desenvolvimento, e também sinalizando algumas de suas limitações e possibilidades futuras.

\section{CONCLUSÕES}

De todos os modelos de sujeito aqui propostos, o sujeitoagente talvez seja o que mais se aproxima de uma estratégia pós-moderna de recomposição do trabalho. Pois se trata de um trabalho muito mais associado a fluxos organizativos do que propriamente à lógica do emprego, com sua estabilidade e contornos relativos. A institucionalização do trabalho enquanto emprego, inclusive, deu ensejo a alguns modelos de carreira marcadamente "essencialistas". Por exemplo, tome-se o conceito de "personalidade vocacional", proposto por Holland (1973). Nessa perspectiva, a carreira seria uma construção inerente ao indivíduo e a seus estados psicológicos internos mais ou menos estáveis. Uma perspectiva correlata, no âmbito da sociologia, seria de que a carreira é o reflexo da estrutura social, restando pouco ou nenhuma margem de flexibilidade ao próprio indivíduo para configurá-la (BLAU \& DUNCAN, 1967). Baseando-nos nas discussões promovidas neste artigo, cremos que ambas essas perspectivas contêm limitações.

Todavia, dizer que o sujeito-agente e seus modelos de carreira correspondentes estão mais próximos das recomposições contemporâneas do trabalho não significa que eles sejam isentos de problemas. E talvez o principal seja a ênfase, às vezes em demasia, colocada sobre a "agência individual", como se o indivíduo fosse o único responsável pelo sucesso ou pelo fracasso de sua carreira. Em nosso entender, tanto essa quanto a limitação anterior, referente à tendência de certas abordagens de "essencializar" a carreira, podem ser superadas pelos modelos interacionistas e construcionistas de carreira. Assim, o sujeito reflexivo, com seus modelos de carreiras respectivos (Quadro 1), podem representar pistas promissoras para pensarmos as carreiras na atualidade.

De um lado, eles admitem as nítidas transformações observadas nos processos de institucionalização do trabalho, como a crescente flexibilização das relações do indivíduo com a organização e também a emergência de novos formatos de trabalho - alguns bem distantes do tradicional modelo do emprego industrial. De outro, e contrariamente aos modelos associados ao sujeito-agente, as perspectivas interacionistas definem as carreiras como produtos das relações psicossociais dinâmicas e dialéticas entre indivíduo, sociedade e organizações de trabalho (e não apenas de uma ou outra dessas dimensões). A carreira é então compreendida como uma construção social, inscrita tanto nos âmbito individual, grupal como societal e organizativo mais amplos. Em nossa opinião, essa perspectiva de análise é a mais rica dentro do quadro esboçado neste artigo, sendo um desafio a condução de investigações empíricas alimentadas por seus postulados.

Para finalizar, gostaríamos de ressaltar algumas limitações deste artigo, na esperança de que isso sirva de ponto de partida para novas investigações. Em primeiro lugar, por se tratar de um ensaio teórico, deve ser seguido de investigações empíricas. Ainda nesse sentido, seria interessante o levantamento dessas investigações e sua integração com vistas a um mapeamento do estado da arte do estudo de campo sobre carreiras. Em segundo lugar, o artigo não se dedicou a uma avaliação da situação local. De fato, vários autores vêm se dedicando ao estudo e à pesquisa das carreiras em nosso país, e isso nas três tradições aqui apontadas - psicologia, sociologia e administração (por exemplo: DUTRA, 1996; COSTA e BALASSIANO, 2006; TOLFO, 2002; BASTOS, 1997; KILIMNIK, SANT'ANNA $\&$ CASTILHO, 2007). Seria altamente relevante um esforço de análise dessa produção local buscando elucidar os pressupostos sobre o sujeito e o trabalho neles implícitos, bem como sua contribuição para a recomposição da relação homem-trabalho no contexto socioeconômico e cultural brasileiro.

\section{REFERÊNCIAS}

ADAMSON, S. J; DOHERTY, N; VINEY, C. The meaning of career revisited. British Journal of Management, v. 9, n. 4, p. 251-259, 1998.

ARTHUR, M. B. The boundaryless career: a new perspective for organizational inquiry. Journal of Organizational Behavior, v. 15, n. 4, p. 295-306, 1994

ARTHUR, M. B; ROUSSEAU, D. (Eds) The Boundaryless Career: Individual Action and Economic Change. New York: Oxford University Press, 1996.

ARTHUR, M. B; HALL, D. T; LAWRENCE, B. S. (Eds) Handbook of Career Theory. Cambridge: Cambridge University Press, 1989.

BANDURA, A. Self-efficacy: toward a unifying theory of behavioral change Psychological Review, v. 84, n. 2, p. 191-215, 1977.

BANDURA, A. Social Foundations of Thought and Action. New Jersey: Prentice-Hall, 1986.

BARUCH, Y. Career development in organizations and beyond: balancing traditional and contemporary viewpoints. Human Resource Management Review, v. 16, n. 2, p. 125-38, 2006 
BARUCH, Y. Transforming careers: from linear to multidirectional careers paths. Career Development International, v. 9, n. 1, p. 58-73, 2004

BASTOS, A. V. A escolha e o comprometimento com a carreira. Revista de Administração da Universidade de São Paulo, v. 32, n. 3, p. 28-39, 1997.

BECK, U; BECK-GERNSHEIM, E. Individualization. London: Sage, 2001.

BETZ, N. E; FITZGERALD, L. F. The Career Psychology of Women. Orlando: Academic Press, 1987

BETZ, N. E; HACKETT, G. Applications of self-efficacy theory to understanding career choice behavior. Journal of Sociological and Clinical Psychology, v. 4, n. 3, p. 279-289, 1986.

BLAU, P. M; DUNCAN, O. D. The American Occupational Structure. New York: Wiley, 1967.

BLUSTEIN, D. L. "Who am I?": the question of self and identity in career development. In: SAVICKAS, M. L; LENT, R. W. (Eds) Convergence in Career Development Theories. Palo Alto, CA: Consulting Psychologists, 1994. p. 139-154.

BLUSTEIN, D. L; SCHULTHEISS, D. E. P; FLUM, H. Toward a relational perspective of the psychology of careers and working: a social constructionist analysis. Journal of Vocational Behavior, v. 64, n. 3, p. 423-440, 2004.

BORGEN, W. A; AMUNDSON, N. E; REUTER, J. Using portfolios to enhance career resilience. Journal of Employment Counseling, v. 41, n. 2 , p. $50-9,2004$

BOUTINET, J. P. Anthropologie du projet. Paris: PUF, 1990.

BUJOLD, C. Constructing career through narrative. Journal of Vocational Behavior, v. 64, n. 3, p. 470-484, 2004.

CARR-SAUnders, A. M; WILSON, P. A. The Professions. Oxford: Clarendon Press, 1933.

CASTEL, R. La montée des incertitudes. Paris: Seuil, 2009.

CASTEL, R. Les métamorphoses de la question sociale. Paris: Gallimard, 1999.

CHAPOUliE, J.-M. La tradition sociologique de Chicago. Paris: Éditions de l'EHESS, 2001.

CHEN, C. P. Integrating action theory and human agency in career development. Canadian Journal of Counselling, v. 36, n. 2, p. 121-135, 2002.

CHEN, C. P. Strengthening career human agency. Journal of Counseling \& Development, v. 84, n. 2, p. 131-138, 2006.

COCHRAN, L; LAUB, J. Becoming an Agent. New York: Suny, 1994.

COCHRAN, L. Career Counseling: A Narrative Approach. London: Sage, 1997.

COCHRAN, L. Narrative as a paradigm for career research. In: YOUNG, R. A; BORGEN, W. A. (Eds) Methodological Approaches to the Study of Career. New York: Praeger, 1990. p. 71-86.
COHEN, L; DUBERLEY, J; MALLON, M. Social constructionism in the study of career. Journal of Vocational Behavior, v. 64, n. 3, p. 407-422, 2004

COLLIN, A; YOUNG, R. A. The future of career. In: COLLIN, A; YOUNG, R. A. (Eds) The Future of Career. Cambridge: Cambridge University Press, 2000. p. $276-300$.

COLLINSON, D. L. Identities and insecurities: selves at work. Organization, v. 10, n. 3, p. 527-547, 2003.

COSTA, I. S. A; BALASSIANO, M. (Orgs) Gestão de carreiras. São Paulo: Atlas, 2006.

CROWLEY-HENRY, M; WEIR, D. The international protean career. Journal of Organizational Change Management, v. 20, n. 2, p. 245-258, 2007.

CROWLEY-HENRY, M. The protean career. International Studies of Management \& Organization, v. 37, n. 3, p. 44-64, 2007.

CSIKSZENTMIHALYI, M. Flow: The Psychology of Optimal Experience. New York: HarperCollins, 1991.

CURRIE, G; TEMPES, S; STARKEY, K. New careers for old? International Journal of Human Resource Management, v. 17, n. 4, p. 755-774, 2006.

DANY, F. Free actors and organizations. International Journal of Human Resource Management, v. 14, n. 5, p. 821-838, 2003.

DEFILLIPPI, J. R; ARTHUR, M. B. The boundaryless career: a competency-based perspective. Journal of Organizational Behavior, v. 15, n. 4, p. 307-24, 1994.

DUBAR, C; TRIPIER, P. Sociologie des professions. Paris: Armand Colin, 2005.

DUBAR, C. La crise des identités. Paris: PUF, 2000

DUBERLEY, J; MALLON, M; COHEN, L. Exploring career transitions: accounting for structure and agency. Personnel Review, v. 35, n. 3, p. 281296,2006

DUBET, F. Role et expérience. In: BARBIER, J.-M. (Ed) Lanalyse de la singularité de l'action. Paris: PUF, 2000. p. 71-84.

DUTRA, J. Administração de carreiras. São Paulo : Atlas, 1996.

EHRENBERG, A. Le culte de la performance. Paris: Calmman-Levy, 1991.

EHRENBERG, A. Lindividu incertain. Paris: Calmman-Levy, 1995.

ELSTER, J. (Ed) The multiple self. Cambridge: Cambridge University Press, 1985.

EVETTS, J. Dimensions of career: avoiding reification in the analysis of change. Sociology, v. 26, n. 1, p. 1-21, 1992

EVETTS, J. The sociology of professional group. Knowledge, Work and Society, v. 1, p. 10-18, 2003 


\section{PEDRO F. BENDASSOLLI}

EZZY, D. Subjectivity and the labour process. Sociology, v. 31, n. 3, p. 427-444, 1997.

FARR, R. The Roots of Modern Social Psychology. Oxford: Blackwell, 1996.

FREIDSON, E. Professionalism Reborn. Cambridge: Cambridge University Press, 1994

GARNER, H; MÉDA, D; SENIK, C. La place du travail dans les identités. Économie et Statistique, n. 393-394, p. 21-40, 2006.

GAY, P. Consumption and Identity at Work. London: Sage, 1996.

GIDDENS, A. Modernity and Self-Identity. London: Polity Press, 1991.

GREY, C. Career as a project of the self and labour process discipline. Sociology, v. 28, n. 2, p. 479-497, 1994.

GUNZ, H. P; PEIPERL, M. A. Handbook of Career Studies. Londres: Sage, 2007.

GUNZ, H. The dual meaning of managerial careers. Journal of Management Studies, v. 26, n. 3, p. 225-250, 1989.

HALL, D. T. Careers in and out of Organizations. Londres: Sage, 2002.

HALL, D. T. Career in Organizations. Glenview: Scott Foresman, 1976.

HALL, D. T. The protean career: a quarter-century journey. Journal of Vocational Behavior, v. 65, n. 1, p. 1-13, 2004.

HEINICH, N. Être écrivain: création et identité. Paris: La Découverte, 2000.

HOLLAND, J. L. Making Vocational Choices. Englewood Cliffs, NJ: Prentice Hall, 1973.

HOLSTEIN, J. A; GRUBRIUM, J. F. Handbook of Constructionist Research. New York: The Guilford Press, 2008.

HONNETH, A. Travail et agir instrumental. Travailler, n. 18, p. 17-58, 2007.

HUGHES, E. C. Institutional office and the person. The American Journal of Sociology, v. 43, n. 3, p. 404-413, 1937.

INKSON, K. Understanding Careers: The Metaphors of Working Lives. Londres: Sage, 2007.

JACKSON, C. Managing and developing a boundaryless career. European Journal of Work and Organizational Psychology, v. 5, n. 4, p. 617-628, 1996.

KADDOURI, M. Le projet de soi entre assignation et authenticité. Recherche et Formation, n. 31, p. 31-48, 2002.

KADDOURI, M. Place du projet dans les dynamiques identitaires. Education Permanente, n. 128, p. 135-151, 1996.
KILIMNIK, Z. M; SANT'ANNA, A. S; CASTILHO, I. V. Carreiras em transformação e seus paradoxais reflexos nos indivíduos. In: BARROS, D. T R; LIMA, M. T; ESCALDA, R. (Orgs) Escolha e inserção profissionais. São Paulo: Vetor, 2007, p. 21-42

KING, Z. Career self-management: its nature, causes and consequences Journal of Vocational Behavior, v. 65, n. 1, p. 112-133, 2004.

KNORR-CETINA, K; CICOUREL, A. V. (Eds) Advances in Social Theory and Methodology. Boston: Routledge, 1981.

LAPLANTE, B. L'étude des carrières professionnelles comme production individuelle. In: MENGER, P.-M. (Ed) Les professions et leurs sociologies. Paris: Maison des Sciences de l'Homme, 2003.

LEGGE, K. Human Resource Management. London: Palgrave Macmillan, 2005.

LEVINSON, D. J. The career is in the life structure, the life structure is in the career. In: ARTHUR, M. B. (Ed) Working with Careers. New York: Columbia University Press, 1984.

LIPS-WIERSMA, M. S; MCMORLAND, J. Finding meaning and purpose in boundaryless careers. Journal of Humanistic Psychology, v. 46, n. 2, p. $147-167,2006$.

MARTUCCELLI, D. Forgé par l'épreuve. Paris: Armand Colin, 2006.

MCDONALD, P; BROWN, K; BRADLEY, L. Have traditional career paths given way to protean ones? Career Development International, v. 10, n. 2 , p. 109-129, 2005.

MEDA, D. Le travail: une valeur en voie de disparition. Paris: Flammarion, 1998.

MENGER, P.-M. Du labeur à l'oeuvre. Paris: Seuil, 2003.

NEVILL, D. D; SCHLECKER, D. I. The relation of self-efficacy and assertiveness to willingness to engage in traditional/nontraditional career activities. Psychology of Women Quarterly, v. 12, n. 1, p. 91-98, 1988.

OSTY, F. Lidentité au travail à l'épreuve de la crise. In: KADDOURI, M. e outros (Orgs) La question identitaire dans le travail et la formation. Paris: L'Harmattan, 2008. p. 69-81.

PARKER, R. N. Structural constraints and individual career earnings patterns. American Sociological Review, v. 46, p. 884-892, 1981.

PARSONS, T. Essays in Sociological Theory. New York: Free Press, 1939.

PERRUCCI, C. C; PERRUCCI, R. Social origins, educational contexts, and career mobility. American Sociological Review, v. 35, n. 3, p. 451-463, 1970.

POEHNELL, G; AMUNDSON, N. Career craft. In: PEIPERL, M; ARTHUR, M. B; ANAND, N. (Eds) Career Creativity. Oxford: Oxford University Press, 2002. p. 105-122.

PRINGLE, J. K; MALLON, M. Challenges for the boundaryless career odyssey. International Journal of human Resource Management, v. 14, n. 5, p. 839-853, 2003. 


\section{ARTIGOS - RECOMPOSIÇÃO DA RELAÇÃO SUJEITO-TRABALHO NOS MODELOS EMERGENTES DE CARREIRA}

RIFKIN, J. The End of Work. New York: Tarcher, 2004.

ROUSSEAU, D. M. Psychological Contracts in Organizations. Londres: Sage, 1995

SARGENT, L. D; DOMBERGER, S. R. Exploring the development of a protean career orientation. Career development international, v. 12, n. 6 , p. $545-564,2007$.

SAVICKAS, M. L. A developmental perspective on vocational behavior: career patterns, salience, and themes. International Journal for Educational and Vocational Guidance, v. 1, p. 49-57, 2001

SAVICKAS, M. L. The theory and practice of career construction. In: BROWN, S. D; LENT, R. W. (Eds) Career Development and Counseling. San Francisco: Jossey-Bass, 2005. p. 42-70.

SCHEIN, E. Career Anchors. San Francisco: University Associates, 1993.

SCHEIN, E. Career Dynamics: Matching Individual and Organizational Needs. Reading, UK: Addison-Wesley, 1978.

SENNETT, R. The Corrosion of Character. New York: Norton, 1998.

STEPHENS, G. K. Crossing internal career boundaries. Journal of Management, v. 20, n. 2, p. 479-501, 1994

STICKLAND, R. Career self-management. International Journal of Work and Organizational Psychology, v. 5, n. 4, p. 583-596, 1996.
SULLIVAN, S. E; ARTHUR, M. B. The evolution of the boundaryless career concept. Journal of Vocational Behavior, v. 69, n. 1, p. 19-29, 2006.

SUPER, D. E; SVERKO, B. (Eds) Life Roles, Values, and Careers. San Francisco: Jossey-Bass, 1995.

SUPER, D. E. A life-span, life-space approach to career development. In BROWN, D; BROOKS, L. (Eds) Career choice and Development: Applying Contemporary Theories to Practice. San Francisco: Jossey-Bass, 1990. p. 197-261.

SUPER, D. E. The Psychology of Careers. Nova York: Harper \& Row, 1957.

TOLFO, S. R. A carreira profissional e seus movimentos. Revista de Psicologia Organizacional e do Trabalho, v. 2, n. 2, p. 39-63, 2002.

ULRICH, K; CARROLL, G. R. Jobs and classes. European Sociological Review, v. 3, n. 1, p. 14-38, 1987.

WALTON, S; MALLON, M. Redefining the boundaries? Asia Pacific Journal of Human Resources, v. 42, n. 1, p. 75-95, 2004.

WOLFGANG, K. La fin des grands projets. L'Orientation Scolaire et Professionnelle, v. 27, n. 1, p. 105-121, 1998.

WRZESNIEWSKI, A; DUTTON, J. E. Crafting a job: revisioning employees as active crafters of their work. Academy of Management Review, v. 26, n. 2, p. 179-201, 2001. 